\title{
RAILWAY INFRASTRUCTURE CAPACITY MANAGEMENT FOR AD HOC TRAINS ON THE SŽDC NETWORK
}

\author{
Petr NachtigalL*， Martin ŠKárek \\ Dopravni fakulta Jana Pernera, Univerzita Pardubice, Studentská 95, 53210 Pardubice \\ * corresponding author: petr.nachtigall@upce.cz
}

Abstract. The paper describes basic principles of ad hoc routes assignment. Each carrier has its own interface called information system KADR with SŽDC for capacity requests management. The paper describes all steps which must be done before train departure

KEYWORDS: Informition system, carrier, ad hoc train, railway infrastructure capacaty.

\section{INTRODUCTION}

For last couple of years is growing volume of request from railway operators to infrastructure manager (SŽDC) for so called ad hoc trains [1. These trains are operated out of the regular construction of the timetable. To make this agenda easier, there was developed an information system called ISOr KADR. The effects of the implementation of this system were in much faster and streamline assignment of the ad hoc routes. Faster is as well the distribution of the time table to all supporting information systems. Among the most important systems which are linked with KADR belong ISOř (Information system for operative control), ComposT (Train composition) and Aport (Preparedness and composition of the train). During autumn 2015 KADR stopped being just a planning program, but it was implemented into the basic operation of the traffic. Via KADR are constructed deflecting routes by traffic incidents and by traffic situation which requires that the train is going on different than basic route. The SŽDC has also competency to set the request instead of the carrier and assign the route and the capacity in one step.

\section{BASIC INFORMATION ABOUT KADR}

Information system KADR has two main parts. There is a web part and a desktop part. The access rights for both parts of the system are restricted by roles in the system. There are five basic roles:

- Carrier - in this role are open up all functions for carriers. This role is available only as a web part,

- Billing - in this role you can use all functions of the program,

- OSS - One stop shop - construction of the route,

- DA - dispatcher - construction of the route,

- Tnack restrictions - construction of the time table by track restriction (available only in desktop part).

Each user must be authorized before entering the KADR software. For authorization there is used the Logserver. On the Logserver are saved all types of roles and for each role are assigned users. After successful authorization the Logserver returns back the role (or more roles) for the user. The system automatically starts the interface with functions and data for user's role [2].

\section{WEB PART OF THE APPLICATION}

The web part of KADR is available anywhere on public internet at the website of the infrastructure manager (http://provoz.szdc.cz/KADR). This part is used mainly by carriers pro submitting of their new requests for assignment of the capacity, for activation and deactivation of trains, for statistics and so on. On the Figure 1 is a basic screen of the web part for the carrier after $\log$ in.

The basic screen has some bookmarks with groups of functions:

- Requests/DJř (day time table) - on this bookmark are all routes of the carrier (including routes from the year time table). Each row is one train and carrier can see their basic information and the application status. At the end of each row are icons for work with each request.

- Activation - this bookmark is for changing of the train status. The carrier can activate the train (train will be really operated), deactivate the train (carrier doesn't use the capacity that day or period), put together some routes and submit a request for re-activation of the detached train.

- Train preparation - carrier can set the analysis of the train and preparation of the train for the departure. Both information are absolutely necessary for train operation.

- Restrictions - link for DOMIN (Database of infrastructure restrictions) application, where can be find actual track restrictions and other incidents.

- Carriers - the list of carriers is in register of the infrastructure manager (SŽDC). This list is in the system called KAFR (Catalogue of carriers). Each carrier can find here basic information about other carriers as well as contacts for responsible people. 


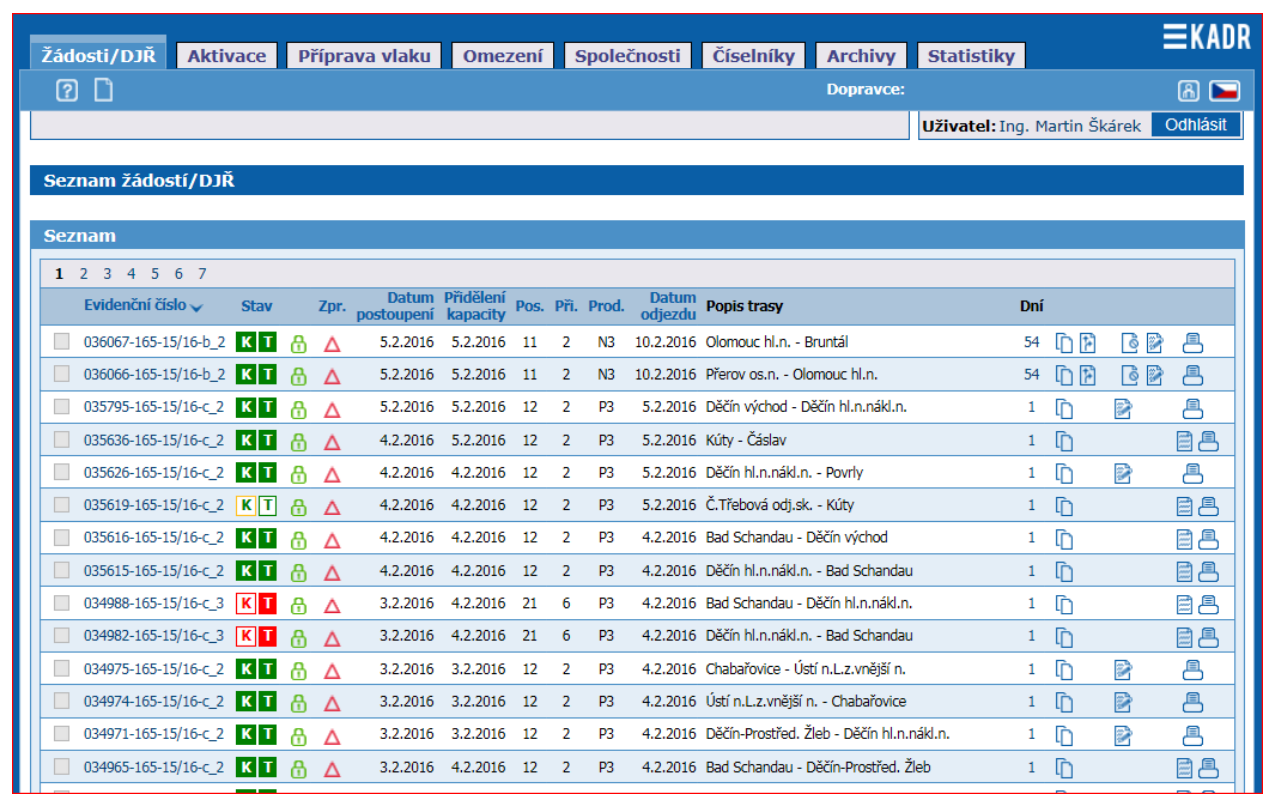

Figure 1. Basic screen of the web part [2].

- Numbered lists - there is an overview of all available numberings, such as:

$\triangleright$ Numbered list of engines - information from the information system REVOZ (Register of engines)

- basic information about engines and special vehicles.

$\triangleright$ Services - there is a numbered list of services, which are offered by infrastructure manager for ad hoc routes.

$\triangleright$ Operations - numbered list of acts, this can be requested by a carrier.

$\triangleright$ Products - numbered list of products, this can be assigned to a request.

- Archive - Archive of data from previous time tables.

- Statistics - carrier has to available 4 types of statistics:

$\triangleright$ Charges for capacity assignment - carrier can see financial costs for capacity assignment for any period.

$\triangleright$ Set of capacity requests - list of all capacity requests. Requests can be filtered or exported according to various parameters.

$\triangleright$ Set of time tables - list of all assigned requests. Requests can be filtered or exported according to various parameters.

$\triangleright$ Day set of time tables - day list of all route of trains. Trains can be filtered or exported according to various parameters.

Probably the most important feature of the web part of KADR is for the carrier submitting of the application. The carrier must fill in step-by-step the following information:

- Schedule - carrier must choose days for which he submits the request. There are three types of requests. Type $\mathrm{c}-$ less than 3 working days (the train departs less than 3 days from the request). Type b - more than 3 working days (the train departs 4 of more days after the request). This distribution is for easier preferences by capacity assignment.

- Route of the request - carrier finds his requested route on the map.

- Basic information about a train - carrier must fill in all mandatory data such as: train engines, weight, length, used type of the brake, category and type of the train.

- Extending data - here are stated other train parameters, transport of dangerous goods, special load, military transport, services on the train.

After completing the entire information carrier is allowed to forward the application to the interfaces of the infrastructure manager.

Next possibility for submit of the request is via data communication, when carrier has its own software which is compatible with KADR. The data interface is in the format of TSI TAF. This requires bidirectional communication between KADR and carrier's information system. This interface shall be in defined format TSI TAF with annexes. Nowadays is valid version 5.17 and during this year will be implemented new version 2.1.

The web part of the application is for the infrastructure manager very similar to the carrier's web part. The infrastructure manager doesn't use this part very often, because most of his usually used functions are in the desktop part.

\section{DESKTOP PART OF THE APPLICATION}

The desktop part of KADR is available only for infrastructure manager. The installation is executed 


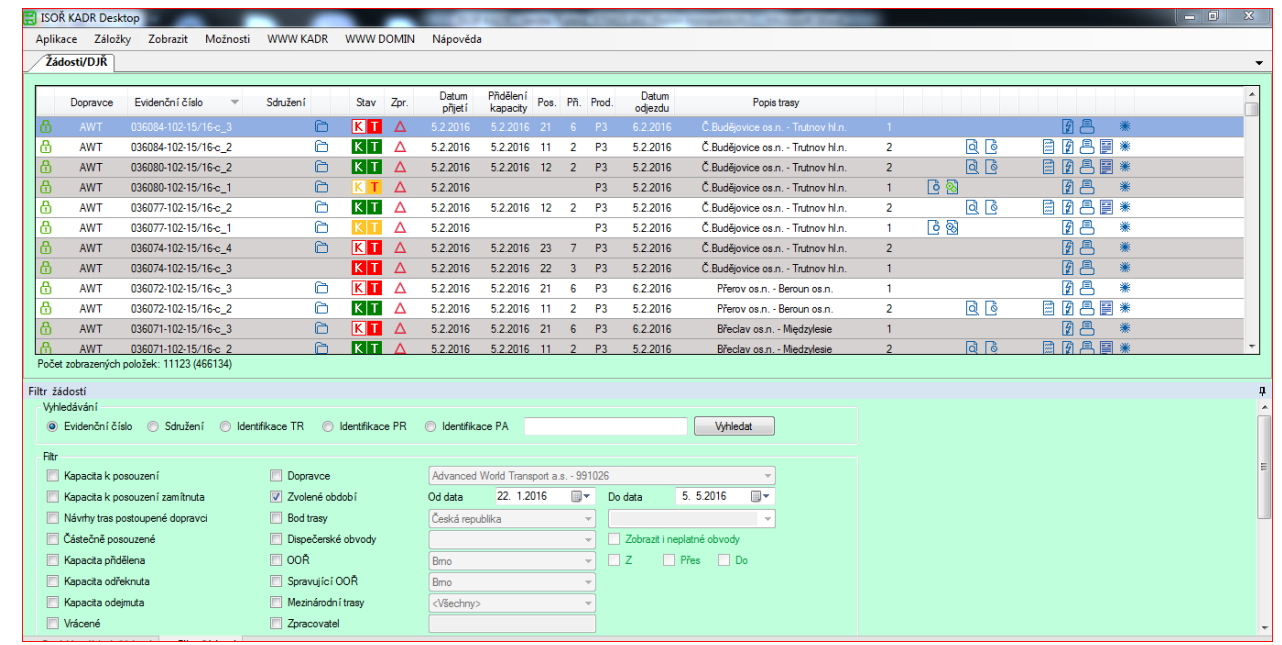

Figure 2. Desktop part of the application [2].

through the web part. The work with the desktop part is possible only from the SŽDC intranet. The infrastructure manager is setting up the time table of ad hoc trains in this part of the application. Here can be also authorized the carrier's request for the ad hoc trains or prepare the aids of the time table like dispatch or tabular time table. The basic screen of the desktop part after authorization is at the Figure 2.

\section{Conclusions}

The information system KADR becomes during its existence one of the most important planning tool for basic operation of the railway transport. Without its existence isn't nowadays possible ride of any train, because KADR secures activation and deactivation of trains and information system ISOR on request of KADR establish the route into all other information systems. The SŽDC offers to all carriers the web part of KADR for free. Each carrier pays only charges and fees for capacity assignment and using of railway infrastructure according to the Czech law [3].

\section{REFERENCES}

[1] Document of Infrastructare manager "Prohlášení o dráze celostátní u regionální".

[2] Internal materials of the company Oltis Group a.s.

[3] Law Nr. 266/1994 Sb., o dráhách. 